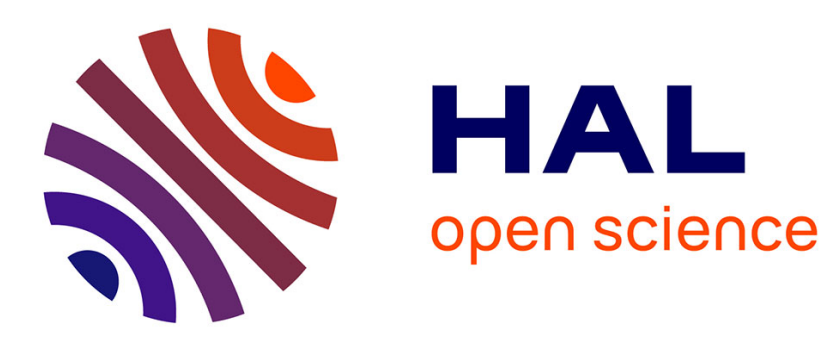

\title{
FEMTOVOLTMETER AND VOLTAGE TUNABLE HETERODYNE RECEIVER BASED ON THE dc RESISTIVE SQUID
}

B. Ulrich, R.W. van Der Heijden, J. Verschueren

\section{- To cite this version:}

B. Ulrich, R.W. van Der Heijden, J. Verschueren. FEMTOVOLTMETER AND VOLTAGE TUNABLE HETERODYNE RECEIVER BASED ON THE dc RESISTIVE SQUID. Journal de Physique Colloques, 1978, 39 (C6), pp.C6-1221-C6-1222. 10.1051/jphyscol:19786540 . jpa-00218028

\section{HAL Id: jpa-00218028 https://hal.science/jpa-00218028}

Submitted on 1 Jan 1978

HAL is a multi-disciplinary open access archive for the deposit and dissemination of scientific research documents, whether they are published or not. The documents may come from teaching and research institutions in France or abroad, or from public or private research centers.
L'archive ouverte pluridisciplinaire HAL, est destinée au dépôt et à la diffusion de documents scientifiques de niveau recherche, publiés ou non, émanant des établissements d'enseignement et de recherche français ou étrangers, des laboratoires publics ou privés. 
Département de Physique de la Matière Condensée, University of Geneva, 24, Quai Ernest Ansermet, 1211 Geneva 4, Switzeriand

*Fysisch Laboratorium, University of Nijmegen, Nimegen, Nethertands

Résumé.- Un voltmètre de sensibilité, $\delta \mathrm{V}=1 \times 10^{-15} \mathrm{~V} /(\mathrm{Hz})^{1 / 2}$, (soit, $\left.1 \mathrm{fV} / \mathrm{(Hz}\right)^{1 / 2}$ ), et un récepteur heterodyne pour l'infrarouge lorms tain, avec la fréquence réglable par tension, et une rêsolution de fréquence intrinsèque de $0,5 \mathrm{~Hz}$ à une fréquence de signal de $0,7 \times 10^{12} \mathrm{~Hz}(0,7 \mathrm{THz})$, avec une efficacité de 0,2 en puissance pour la deuxième conversion, a été construit sur la base d'un "dc resistive SQUID".

Abstract.- A voltmeter with femtovolt sensitivity, $\delta V_{\mathrm{rms}}=1 \times 10^{-15} \mathrm{~V} /(\mathrm{Hz})^{1 / 2}$, (i.e., $1 \mathrm{fV} /$ $\left.(\mathrm{Hz})^{1} /{ }^{2}\right)$, and a voltage tunable far infrared heterodyne receiver, with intrinsic frequency resolution of $0.5 \mathrm{~Hz}$ at signal frequency $0.7 \times 10^{12} \mathrm{~Hz}(0.7 \mathrm{THz})$ and a second power conversion efficiency of 0.2 , were constructed on the basis of a dc resistive SQUID.

The dc resistive SQUID ( $d c$ R-SQUID) can act as a sensitive voltage amplifier $/ 1,2 /$ through direct voltage to frequency conversion, as a null detector for a negative feedback voltage amplifier, and also as a mixing element in a voltage tunable heterodyne receiver. The key difference between the usual dc SQUID and the dc R-SQUID is the normal section of figure $1 \mathrm{a}$, the resistance of figure $1 \mathrm{~b}$ included in the superconducting loop containing two Josephson junctions. The voltage sensitivity of the amplifier, as well as the frequency resolution and the tuning range of the mixer are directly proportional to $\mathrm{R}$. These parameters can be varied by choosing $R$.

As a femtovoltmeter or sensitive voltage amplifier, the voltage to frequency convertor (VF) mode is particularly suited for measurement of small voltage differences $V$ directly across a sample. Due to its smaller total size, the VF mode is less subject to spurious voltages produced by thermal gradients, than the negative feedback amplifier. The VF mode is absolute in that a frequency is measured; no low temperature reference resistor is required. The negative feedback mode, similar to that for an rf SQUID $13,4 /$; is useful to raise the input impedance of the amplifier, and to produce a voltage out put directly proportional to the input voltage $v$.

The dc R-SQUID operates 1 ike a totally superconducting de SQUID $/ 5 /$, except that the relative junction phase $\phi=\phi_{2}-\phi_{1}$ now contains a contribution $2 \pi f\left(V / \Phi_{0}\right) d t$ from the voltage across $R$, as well as the magnetic flux contribution $2 \pi \Phi / \Phi_{0}$, where $\Phi_{0}=h / 2 e$ is the quantum of magnetic flux. The interferometer critical current remains periodic in $\phi$ with period $2 \pi$. At constant magnetic flux, when $V$ is nonzero, the critical current $I_{c}(\phi)$ oscillates at frequency $f_{V}=V / \Phi_{O}$. For constant bias current $I_{b}$, the resulting bias voltage oscillation $\Delta V_{2}$ can be observed as shown in figure $1 \mathrm{c}$. Johnson-Nyquist voltage fluctuations in $R$ broaden the line at $f_{V}$ to about $\delta f_{V}=\delta V_{\mathrm{rms}} / \Phi_{O} \backsim\left(2 \mathrm{k}_{\mathrm{B}} \mathrm{T} / \pi \mathrm{L}\right)^{\mathrm{I} / 2} \mathrm{R} / \Phi_{\nu}$, limiting the voltage sensitivity to $\delta \mathrm{V}_{\mathrm{rms}} /(\mathrm{Hz})^{1 / 2}$, where $\mathrm{T}$ is the temperature of $R$, and $L$ the inductance of the loop containing the junctions.

The present experiments $/ 6 /$ used point contact junctions in the geometry of figure $1 a$, with a $30 \mu \mathrm{m}$ thick copper foil resistor $\mathrm{R}$, with $\mathrm{PbSn}$ solder electrodes melted on opposite sides over a $0.5 \mathrm{~cm}^{2}$ area. The resistance $\mathrm{R}=3.3 \times 10^{-9} \Omega$ was measured to be linear via the voltage to frequency relation $f_{V}=R I / \Phi_{0}+$ const, for measured injected currents I. Voltage resolution $\delta \mathrm{V}_{\mathrm{rms}}=1 \times 10^{-15} \mathrm{~V} /(\mathrm{Hz})^{1 / 2}$ was determined from the measured linewidth $\delta f_{\mathrm{V}}=0.5 \mathrm{~Hz}$ Applications of a voltage tunable far infrared heterodyne receiver include astronomical observations of interstellar molecular line emission, laboratory spectroscopy, and plasma diagnostics such as Thomson scattering for measurement of ion temperature, and rapid frequency scan of electron cyclotron emission to observe the time evolution of the electron temperature spatial distribution in the p1 asma. 
As a mixer $/ 2 /$, the de R-SQUID is particularly useful in the far infrared where laser lines $f_{L}$ suitable as a local oscillator may not lie near the desired signal frequency $f_{S}$. Here, the internal oscillation of the $d c$ R-SQUID can span the gap between $f_{L}$ and $f_{S}$ to arrive at a convenient intermediate frequency $\bar{f}_{I}=f_{S}-f_{L}-f_{V}$, or to scan the spectrum of the signal by varying the current $I$ injected into $R$. The intrinsic frequency resolution, determined by $\delta f_{V}$ is proportional to $R$. Linewidths can be much narrower than in the single junction self-oscillating mixer $/ 7 /$. Typical values of $\mathrm{R}$ range from $10^{-9} \Omega$ to $10^{-3} \Omega$ for frequency resolutions from $1 \mathrm{~Hz}$ to $10^{6} \mathrm{~Hz}$. The tuning range for convenient $I$ is also proportional to $R$. Although typical values of $R$ are sma11, the input impedance at the signal frequency depends on the junction normal shunt resistance $R_{N}$, which, for point contact junctions, can be tens to hundreds of ohms to facilitate signal coupling. The double junction structure can be designed as an antenna to couple to the signal.

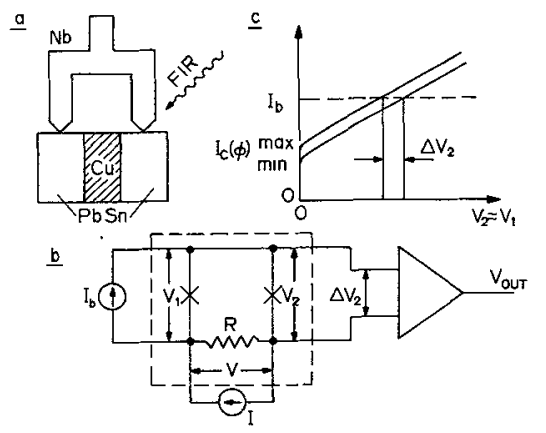

Fig. 1 : The dc R-SQUID used as a femtovoltmeter and voltage tunable far infrared (FIR) heterodyne receiver was constructed with point contact geometry (a), described by the simplified equivalent circuit (b) in which the portion inside dashed 1ines was located at liquid helium temperature. The readout mode (c) assumes that the sample resistance $R$ is several orders of magnitude smaller than the junction normal resistance $R_{N}$.

Mixing in a de R-SQUID with an external local oscillator is best viewed as a two step process, $f_{S} \rightarrow f_{D}=f_{S}-f_{L} \rightarrow f_{I}=f_{D}-f_{V}$. The Eirst step occurs in a manner similar to mixing in a single Josephson junction. The second step from $f_{D}$ to $f_{I}$ occurs with power conversion efficiency $n_{2}$. The second conversion efficiency $\eta_{2}$ is the additional cost for the convenience of voltage tunability, a cost that in practice can be recovered through lower i.f. amplifier noise temperature by reducing $f_{I}$ to the lowest frequency consistent with the required signal bandwidth. Values of $n_{2}$ up to 0.2 were observed experimentally /8/. A fornic acid laser line at $693 \mu \mathrm{m}(0.7 \mathrm{THz})$ served as local oscillator, part of which was split off and Doppler shifted by amounts $\mathrm{f}_{\mathrm{D}}$ ranging from $100 \mathrm{~Hz}$ to $50 \mathrm{kHz}$ to serve as signal. The sum and difference components $f_{+}=f_{D}-f_{V}$, and $f_{-}=f_{I}=f_{D}-f_{V}$ were observed with an audio frequency spectrum analyzer after preamplification, and found to be of equal intensity. Intrinsic frequency resolution, determined by $\delta f_{V}=0.5 \mathrm{~Hz}$, was 1 part in $10^{12}$.

The authors thank $P$. Wyder, J. Sierro, and B. Giovannini for their encouragement, and $L$. Coenen and $R$. Cartoni for their technical support. Support of the Netherlands Foundation for Fundamental Research (FOM branch of ZWO), and of NASA is gratefully acknowledged.

\section{References}

/1/ Ulrich, B.T., Zeitschrift für angewandte Mathematik und Physik 29 (1978) 13

/2/ Ulrich, B.T., in preparation

/3/ Giffard, R.P., Webb, R.A. and Wheatley, J.C., J. Low Temp. Phys. 6 (1972) 533

14/ Davidson, A., Newbower, R.S. and Beasley, M.R., Rev. Sci. Instr. 45 (1974) 838

/5/ Tesche, C.D. and Clarke, J., J. Low Temp. Phys. 29 (1977) 301

/6/ Ulrich, B.T. and Verschueren, J.M.V., in preparation.

/7/ Vernet, G. and Adde, R., Rev. Phys. Appl. 9 (1974) 275

/8/ Ulrich, B.T., Van der Heijden, R.W. and Verschueren, J.M.V., in preparation. 